6. J. Leray and J. Schauder, Topologie et equations fonctionnelles, Ann. Sci. Ecole Norm. Sup. (3) 5 (1934), 45-78.

7. M. Nagumo, Degree of mapping in convex topological spaces, Amer. J. Math. 73 (1951), 497-511.

8. E. H. Rothe, Gradient mappings in Banach spaces, Duke Math. J. 15 (1948), $421-431$.

UNIVERSITY OF MiNNESOTA

\title{
COEFFICIENT ESTIMATES FOR UNIVALENT FUNCTIONS
}

\author{
P. L. DUREN
}

Let

$$
f(z)=z+b_{1} / z+b_{2} / z^{2}+\cdots
$$

be analytic and univalent in $|z|>1$. It is an immediate consequence of the area theorem that $\left|b_{1}\right| \leqq 1$. In 1938 Schiffer [5], using a variational method, and Golusin [2] independently derived the sharp inequality $\left|b_{2}\right| \leqq 2 / 3$. It was then conjectured that $\left|b_{n}\right| \leqq 2 /(n+1)$, but this proved to be false without additional hypotheses. Indeed, Garabedian and Schiffer [1] found the true bound for $\left|b_{3}\right|$ to be $1 / 2+e^{-6}$. A theorem of Golusin [2], however, asserts the following:

THEOREM. Let $f(z)$ be analytic and univalent in $|z|>1$ and have the expansion (1). For some $N \geqq 1$, let $b_{1}=b_{2}=\cdots=b_{N-1}=0$. Then $\left|b_{n}\right| \leqq 2 /(n+1)$ for $n=N, N+1, \cdots, 2 N$. (In particular, $\left|b_{2}\right| \leqq 2 / 3$.)

Jenkins [4] has recently obtained this result by means of his General Coefficient Theorem. It is the purpose of the present note to give a simple proof. Clearly, it suffices to show $\left|b_{2 N-1}\right| \leqq 1 / N$ and $\left|b_{2 N}\right| \leqq 2 /(2 N+1)$.

The $n$th Faber polynomial $F_{n}(w)$ associated with the function (1) is defined by

$$
F_{n}[f(z)]=z^{n}+\sum_{m=1}^{\infty} \beta_{n m} z^{-m}
$$

The following inequalities, due to Grunsky [3], constitute an elementary generalization of the area theorem: 1960.

Presented to the Society, August 29, 1961; received by the editors December 17, 


$$
\left|\sum_{n, m=1}^{N} m \beta_{n m} x_{n} x_{m}\right| \leqq \sum_{n=1}^{N} n\left|x_{n}\right|^{2}
$$

for each $N$ an arbitrary complex $x_{1}, x_{2}, \cdots, x_{N}$. In particular,

$$
\left|\beta_{N N}\right| \leqq 1 \text {. }
$$

Now suppose $b_{1}=b_{2}=\cdots=b_{N-1}=0$ in (1). Then

$$
\begin{aligned}
{[f(z)]^{N}=} & z^{N}\left[1+b_{N} / z^{N+1}+b_{N+1} / z^{N+2}+\cdots\right]^{N} \\
= & z^{N}\left\{1+N\left(b_{N} / z^{N+1}+\cdots\right)\right. \\
& \left.+\frac{N(N-1)}{2 !}\left(b_{N} / z^{N+1}+\cdots\right)^{2}+\cdots\right\} .
\end{aligned}
$$

Hence $F_{N}[f(z)]=[f(z)]^{N}$, and $\beta_{N N}=N b_{2 N-1}$. Therefore, by (2), $\left|b_{2 N-1}\right| \leqq 1 / N$.

To estimate $\left|b_{2 N}\right|$, consider the function

$$
\begin{aligned}
g(z) & =\left(f\left(z^{2}\right)\right)^{1 / 2}=z\left[1+b_{N} / z^{2 N+2}+b_{N+1} / z^{2 N+4}+\cdots\right]^{1 / 2} \\
& =z\left\{1+1 / 2\left(b_{N} / z^{2 N+2}+\cdots\right)-1 / 8\left(b_{N} / z^{2 N+2}+\cdots\right)^{2}+\cdots\right\} \\
& =z+\sum_{j=1}^{\infty} c_{j} z^{-j}, \text { say. }
\end{aligned}
$$

Here $c_{j}=0$ for $j \leqq 2 N+1$, so $\left|c_{4 N+1}\right| \leqq 1 /(2 N+1)$, by what has just been proved. But $c_{4 N+1}=(1 / 2) b_{2 N}$, so $\left|b_{2 N}\right| \leqq 2 /(2 N+1)$, which finishes the proof.

I wish to thank Professor Schiffer for several very helpful suggestions.

\section{REFERENCES}

1. P. R. Garabedian and M. Schiffer, A coefficient inequality for schlicht functions, Ann. of Math. vol. 61 (1955) pp. 116-136.

2. G. M. Golusin, Some estimates of the coefficients of schlicht functions, Mat. Sb. vol. 3 (1938) pp. 321-330 (in Russian).

3. H. Grunsky, Koeffizientenbedingungen für schlicht abbildende Funktionen, Math. Z. vol. 45 (1939) pp. $29-61$.

4. J. A. Jenkins, On certain coefficients of univalent functions. II, Trans. Amer. Math. Soc. vol. 96 (1960) pp. 534-545.

5. M. Schiffer, Sur un probleme d'extremum de la representation conforme, Bull. Soc. Math. France vol. 66 (1938) pp. 48-55.

STANFORD UNIVERSITY 